\title{
„Den Bösen sind sie los" Überlegungen zu Mephistopheles und zum Bösen in Goethes Faust
}

\begin{abstract}
What's the reason for Mephistopheles in Goethe's Faust being less malicious than one might expect? Taking its cue from that question, this article discusses the figure of the devil in the European imaginary of the $16^{\text {th }}$ century, especially in Christopher Marlowe's Doctor Faustus. Some principal characteristics of Goethe's secular devil are analysed. Goethe's Mephistopheles neither is the demon found in Christian mythology nor represents the villain of the piece. Goethe holds the human characters of both parts of his Faust responsible for the evil that occurs.
\end{abstract}

Keywords: Mephistopheles; Goethe; Marlowe; Faust; the Evil.

Resumo: Por que o Mefistófeles no Fausto de Goethe, ao contrário de todas as expectativas, não apresenta uma natureza realmente má? Partindo desta pergunta, neste artigo discute-se a figura do diabo no imaginário europeu no sec. XVI e no Doctor Faustus de Christopher Marlowe. Em seguida são analisados alguns traços principais do diabo goethiano secularizado. O Mefistófeles de Goethe não é o demônio da mitologia cristã e tão pouco representa o grande vilão da peça. Seu autor deixa claro que a responsibilidade pelo mal produzido nas duas partes do Fausto é dos seus personagens humanos.

Palavras-chave: Mefistófeles; Goethe; Marlowe; Fausto; o mal.

Stichwörter: Mephistopheles; Goethe; Faust; Marlowe; das Böse.

* Der Autor war bis 2002 DAAD-Lektor an der Universidade Federal de Paraná. 
Von allen Figuren, die in Goethes Faust auftreten, ist Mephistopheles sicherlich die schillerndste. Nicht nur dass seine äußere Gestalt den Umständen entsprechend wechselt, noch vielgestaltiger sind seine charakterlichen Eigenschaften: oft spöttisch-ironisch, manchmal deklamatorisch, manchmal kurz angebunden, offen und ehrlich, lügnerisch, zynisch-brutal, aber auch mitfühlend, selbstsicher, schwach, misstrauisch, weise, weltmännisch, zivilisiert, grob - die Liste der Attribute ließe sich fortsetzen, nichts Menschliches scheint ihm fremd zu sein. Gerade deshalb konnte Gustav Gründgens mit seinem Ansatz, Mephisto als den Universalen darzustellen, seit Anfang der dreißiger Jahre in Deutschland so großen Erfolg haben.

Allerdings mangelt es diesem Mephistopheles an einer für den Teufel grundlegenden Eigenschaft: Er ist nicht radikal böse. Schon die Zeitgenossen haben das erkannt und auch kritisiert; im Gespräch mit Goethe am Jahresende 1803 wünschte sich eine seiner prominenten Leserinnen, Madame de Staël, den Teufel grimmiger. Durch und durch diabolische Gestalten gab es in der zeitgenössischen Literatur zur Genüge. In den ersten drei Jahrzehnten des 19. Jahrhunderts, als der zweite Teil des Faust entstand, wurde in Westeuropa mit der gothic novel, dem roman noir bzw. dem Schauerroman ein Genre populär, in dem das unerklärlich Böse als Nachtseite der menschlichen Natur auftrat. Verglichen mit einigen Furcht und Schrekken verbreitenden Gestalten dieser Literatur kann Goethes Mephisto nur harmlos erscheinen. ${ }^{1}$

Man mag einen Vergleich des Faust mit der zeitgenössischen Trivialliteratur für unangemessen halten, doch auch mit der Bösartigkeit etwa des Satans in Miltons Paradise Lost kann Mephistopheles nicht mithalten. Selbst menschliche Bühnenfiguren Shakespeares und Lessings (der beiden Dramatiker, die Goethe besonders schätzte) wie Jago aus Macbeth oder Marinelli aus der Emilia Galotti haben zweifellos viel teuflischere Züge, denn sie sind moralisch zutiefst verkommen und handeln wirklich böse. Dagegen weckt Mephisto, wenn er im ersten Dialog mit Faust das Böse als sein eigentliches

1 Goethe selbst hat von den ,Nacht- und Grabdichtern' (so Goethes Formulierung nach V. 5298), deren Nachfahre Stephen King heutzutage ein Lieblingsautor deutscher Germanistikstudenten ist, überhaupt nichts gehalten, vgl. seine Bemerkungen in einem Gespräch mit Soret 1830, zitiert im letzten Abschnitt. 
Element bezeichnet (V. 1343f.), Erwartungen, die er im weiteren Fortgang der Tragödie nicht erfüllt. Susan Neiman meint: „Quando ele se descreve como alguém que representa o mal, é de perguntar se ele algum dia será capaz de ser o mal“" (Neiman 2003: 306). Er wird es bis zum Schluss nicht.

Goethes Mephistophelesfigur steht damit konträr zu einer europäischen Mentalitätsgeschichte, die viele Jahrhunderte lang von einem fundamentalen christlichen Dualismus bestimmt war und entsprechend schreckliche Bilder von Satan oder Luzifer kannte. Darauf wird zunächst im folgenden Abschnitt eingegangen und unter dieser Perspektive Christopher Marlowes Fauststück vorgestellt. Die anschließenden drei Abschnitte stellen jeweils einen aus meiner Sicht zentralen Aspekt von Goethes Mephistofigur in den Vordergrund. Zum Schluss soll erörtert werden, wie Goethe das Problem des Teufels behandelt und welche Bedeutung das Böse im Faustdrama hat.

\section{Der christliche Teufel und Marlowes Mephistopheles}

Für die von der christlichen Zweiweltenlehre geprägten Menschen des Mittelalters machte das Leben nur Sinn bezogen auf das Jenseits, und alle menschlichen Handlungen mussten sich danach befragen lassen, ob sie in den Himmel oder in die Hölle führten. Dort regierten die Teufel, die auch auf der Erde mächtig waren; allerdings war man ihnen nicht hilflos ausgeliefert. Durch Befolgung der kirchlichen Gebote, mittels Buße, auch Askese, durch Almosen und Gaben sicherte man seinen Platz im Paradies; Unterstützung kam dabei von Engeln und Heiligen. Der mittelalterliche Teufel konnte das ewige Heil des Menschen im Grunde nicht verhindern.

Dies änderte sich im 16. und 17. Jahrhundert, als erste Zweifel am Dualismus der Zweiweltenlehre laut wurden. Das kirchliche Teufelsbild verschärfte sich, gleichzeitig nahm die Angst vor dem Bösen in allen gesellschaftlichen Gruppen zu und Europa wurde Schauplatz blutiger Hexenverfolgungen. Der Teufel als Gestalt des kollektiven Imaginären hatte damals seine große Zeit, unter Katholiken ebenso wie unter Lutheranern oder Anglikanern.

Ein Beispiel dafür sind die Vorstellungen der ersten Jesuiten, die 1549 nach Brasilien kamen. Das halbe Dutzend Soldaten Christi stand vor der 
Aufgabe, den katholischen Glauben in einem Gebiet zu verbreiten, in dem das Böse regierte. Auch wenn die tropische Natur der Küste Bahias die Europäer an das Paradies erinnerte: Die dort lebenden Menschen, die nie das Wort Gottes gehört hatten, wurden von den Jesuiten entweder als Söhne des Teufels oder als Tiere gesehen (Vieira predigte erst hundert Jahre später). Die Aufgabe hieß Katechese, wobei jeder Getaufte einen kleinen Sieg über den Bösen, den spirituellen Herrn der Kolonie, bedeutete. Die Jesuiten hatten es nicht leicht, denn Ideen wie die der Erbsünde, des Bösen, der Hölle, aber auch der Gnade und Erlösung waren den animistisch-naturreligiösen Vorstellungen der indianischen Völker völlig fremd. Als Waffen im Kampf um die indianischen Seelen entstanden die religiös-didaktischen Stücke des Padre Anchieta, die erste schriftlich festgehaltene Literatur auf brasilianischem Boden: „Com o fim de converter o nativo Anchieta engenhou uma poesia e um teatro cujo correlato imaginário é um mundo maniqueísta cindido entre forças em perpétua luta: Tupã; Deus, com sua constelação familiar de anjos e santos, e Anhangá; Demônio, com a sua corte de espíritos malévolos que se fazem presentes nas cerimônias tupis.“ (Bosi 2001: 67f.)

Wie Curupira, Boitatá und einige andere Waldgeister war auch Anhangá jemand, der den Indios Angst machen konnte. Solche Figuren der indianischen Mythologie zu dämonisieren und dabei im christlichen Sinne umzufunktionieren war Teil der jesuitischen Pädagogik, die versuchte, an Vorstellungen im Bewusstsein der Indios anzuknüpfen. Ähnlich erging es übrigens einer orixá-Gottheit der afro-brasilianischen Sklaven. Unter dem Druck des Katholizismus wurde Exu im Laufe der Zeit dämonisiert und mit dem Aufkommen der umbanda zur Personifikation des Bösen. Dieser Prozess ist erst im Verlauf der letzten Jahrzehnte revidiert worden (s. Prandi 2001).

Mitte des 16. Jahrhunderts, als die Jesuiten die brasilianischen Indios mit dem Teufel bekannt machten, bildete sich in Mitteleuropa die FaustTradition heraus. Es war eine Zeit des radikalen Umbruchs in allen gesellschaftlichen Bereichen, eine Zeit, in der die alten Gewissheiten zerbrachen und Europa durch Reformation und Gegenreformation konfessionell gespalten war. Die früheste literarische Fassung des Faust-Motivs, die Historia von D. Johann Fausten von 1587, erschien ohne Verfasserangabe in einem lutheranisch ausgerichteten Frankfurter Verlag. Wie der Held der Historia 
ist der Teufel eine eher simpel angelegte Figur. Von Anfang an lässt Mephostophiles, wie er dort heißt, keinen Zweifel an seiner Identität; er ist nicht mehr und nicht weniger als ein Funktionär der christlichen Hölle. Den Skeptiker Faustus braucht er nicht groß zu verführen. Faustus ,,meynet der Teuffel wer nit so schwartz / als man jhn mahlet / noch die Hell so heiß / wie mann davon sagte", heißt es am Ende des 4. Kapitels (Historia: 21). Später, als der Pakt zwischen den beiden geschlossen ist, wird Faustus' Unglaube so beschrieben: „Doctor Faustus lebt also im Epicurischen Leben Tag vnd Nacht / glaubet nit daß ein GOTT / Hell oder Teuffel were / vermeinet Leib vnd Seele stuerbe miteinander." Um keinen Zweifel daran aufkommen zu lassen, welche Konsequenzen solche freigeistigen Auffassungen haben werden, befassen sich die Kapitel 11-16 ausschließlich mit dem Bösen, schildern ausführlich die Gestalt diverser Teufel und die grauenvollen Zustände in der Hölle.

Die Historia ist ein Stück Warnliteratur aus dem Geist der lutherischen Orthodoxie; entsprechend verhängnisvoll ist ihr Ausgang. Immer wenn sich im Laufe der Zeit bei Faustus Gewissensbisse regen, die ihn vom Weg des Bösen abbringen könnten, droht der Teufel, ihn zu zerstükkeln, den Kopf abzureißen u. a. mehr. Nach Ablauf der Frist von 24 Jahren finden Faustus' Studenten dann seinen grässlich entstellten Körper in der blutbespritzten Wohnung. Wie eine antike Fabel endet die Historia mit einer Moral; die letzten Zeilen sind ein Zitat aus dem 1. Brief des Apostels Petrus in der Übersetzung Luthers: „Seyt nuechtern und wachet / denn ewer Widersacher der Teuffel geht vmbher wie ein bruellender Loewe / vnd suchet welchen er verschlinge / dem widerstehet fest im Glauben." (Historia: 124)

Die bedeutendste Faustdichtung vor Goethe, Christopher Marlowes The Tragical History of Doctor Faustus, irgendwann zwischen 1588 und 1593 entstanden, basiert in ihrem Stoff auf einer englischen Übersetzung des deutschen Faustbuches. Im Unterschied zur Historia, die heutzutage eher von literaturhistorischem Interesse ist, hat Marlowes Stück auch über vierhundert Jahre später nicht an Faszinationskraft verloren. Sein Doctor Faustus ist ein selbstbewusster Renaissancegelehrter, der sich mit den bestehenden Grenzen nicht abfinden will und deshalb einen Pakt mit dem Teufel eingeht, „to practise more than heavenly power permits“ (Epilogue, 
Marlowe 1998: 183). ${ }^{2}$ Von diesem Zeitpunkt an ist er ein Verlorener, a fallen man, dessen magische Tricks über das mit Ablauf der Frist bevorstehende schreckliche Ende nicht hinwegtäuschen können.

Sicherlich bildet die christliche Zweiweltenlehre den Hintergrund, vor dem das Stück verstanden werden muss. Vergleichbar dem mittelalterlichen Mysterienspiel oder morality play werden das Gute und das Böse durch bestimmte Figuren repräsentiert: den guten wie den bösen Engel, den alten Mann im Schlussakt, Cornelius und Valdes sowie Mephistopheles als Vertreter Luzifers.

Faustus' Zweifel am Jenseits werden vor allem in den ersten Gesprächen zwischen ihm und Mephistopheles ausgesprochen. „I think hell's a fable“ äußert Faustus ausgerechnet dem Repräsentanten der Hölle gegenüber, worauf ihm Mephisto entgegnet: „Ay, think so still, till experience change thy mind" (MARLowe 1998: 154). Im Anschluss daran wiederholt sich Faustus noch einmal mit anderen Worten und erklärt auf diese Weise, warum er einen Vertrag eingehen konnte, in dem er seine Seele Luzifer vermacht: „Think'st thou that Faustus is so fond / To imagine that after this life there is any pain? / Tush, these are trifles and mere old wives' tales“. „Ammenmärchen und Altweibergeschichten“- hier spricht ein Freidenker, der am Ende für seinen Unglauben teuer bezahlen muss. Dass der Autor, der von Zeitgenossen des Atheismus beschuldigt wurde, mit dieser Ansicht seines Helden sympathisierte, darf vermutet werden.

Beim ersten Zusammentreffen der beiden Antagonisten noch vor der Unterzeichnung des Paktes sind ihre Positionen merkwürdig verdreht; hier zeigt die Mephistophelesfigur, verglichen mit dem Faustbuch, ganz neue Eigenschaften. Auf Faustus' Frage, warum Mephistopheles sich nicht in der Hölle aufhalte (sondern hier auf der Erde), antwortet der Teufel:

Why, this is hell, nor am I out of it. Thinkst'st thou that I, who saw the face of God And tasted the eternal joys of heaven, Am not

2 Zitiert wird aus dem A-Text nach der Ausgabe von D. Bevington und E. Rasmussen, Oxford World Classics Paperback, zuerst 1995, ansonsten, wenn besonders angegeben, auch aus dem umfangreicheren B-Text, ebenda. Die Schreibung des Namens Mephistopheles ist in beiden Texten normalisiert. 
tormented with ten thousand hells In beeing deprived of everlasting bliss? (MARLOWE 1998: 147)

„Hier (auf der Erde) ist die Hölle, und ich bin in ihr“": Im Grunde erklärt er damit die Hölle zu einer spirituellen Angelegenheit. ${ }^{3}$ Faustus' Reaktion darauf ist der großspurige Ratschlag an den verzweifelten Teufel, er solle sich zusammenreißen und ein Beispiel an ihm selbst, Faustus, nehmen: „Learn thou of Faustus mainly fortitude / And scorn those joys thou never shalt posses“ (MARLOWE 1998: 147). Es ist ein Stück verkehrte Welt, was hier aufgeführt wird: Der Teufel wird nicht als der böse, hinterlistige Verführer eingeführt, sondern als deprimiertes, melancholisches Wesen (,a melancholy demon", Mc ALINDON 1994: 38), das dem Verlust der Himmelsfreuden nachtrauert, während sein eigentliches, Opfer k kraftmeierische Sprüche klopft und sich Illusionen über den Zustand der Welt hingibt.

Abgesehen von diesem Eingangsdisput bleibt Marlowes Mephistopheles-Figur jedoch innerhalb der vorgegebenen Rolle des christlichen Teufels. Er ist für die Zeit des Paktes Faustus' Handlanger, der droht und einschüchtert, wenn sich dessen Gewissen meldet. Einmal holt er sogar Luzifer persönlich, um zu verhindern, dass Faustus seinen Pakt bereut und sich Gott zuwendet. Schließlich erweist sich die Hölle doch nicht als rein spirituell, sondern höchst real. Im B-Text lässt der böse Engel Faustus nur eine Stunde vor seinem Ende einen Blick in die Hölle tun und beschreibt ihm und den Lesern bzw. Zuschauern in 12 Zeilen dieses ,vast perpetual torture-house“ (MARLOWE 1998: 242).

Auch bei Marlowe gibt es keine Rettung. In einem grandiosen Schlussmonolog beklagt Faustus seine bevorstehenden ewigen Höllenqualen und wird abschließend vom Teufel geholt. Im Verlauf des Dramas, vor allem in seinen letzten Szenen, hat die Hauptfigur vorher zunehmend an Tiefe gewonnen. Was ihr zu schaffen macht, ist die Existenz auf Abruf, das unwei-

3 „Indeed, Mephistopheles' account of his own spiritual condition might seem to encourage a metaphorical notion of hell as a state of mind [...] rather than a place of physical torment.“ (MARLowE: Introduction, p. xiii) Mephistopheles' Antwort auf Faustus' spätere Frage „Tell me, where is the place that man call hell?"“ (MARLOWE: 154) geht ebenfalls in diese Richtung. 
gerlich bevorstehende Ende in dem Moment, in dem die 24-Jahrfrist und damit das Leben endet. Im B-Text wird das besonders deutlich: „What are thou, Faustus, but a man condemned to die?" (MArLowe 1998: 229) redet sich der Held - von der Handlung her völlig unmotiviert - mitten in einem seiner groben Streiche selbst an. Am Schluss gewinnt das unabänderliche Fortschreiten der Zeit noch einmal Dramatik: Faustus' letzter Tag läuft ab, die Uhr schlägt elf, dann halb zwölf, dann Mitternacht, während der Verzweifelte sein Schicksal beklagt. Seine Todesangst kann auch heute noch berühren, weil sie existenziell menschlich ist. Obwohl fest eingespannt zwischen Himmel und Hölle, hat Marlowes Doctor Faustus soviel eigenes Gewicht, dass diese Figur auch unabhängig von den religiösen Implikationen lesbar ist (dazu WatT 1997).

Schon zu Marlowes Zeit wird dies die Attraktivität des Stücks ausgemacht haben; auch die Skeptiker im Publikum, die durch Höllenqualen und ewige Verdammnis nicht mehr zu beeindrucken waren, wurden dadurch angesprochen. Schopenhauers Auffassung des Faust-Paktes gilt für Marlowes Faustus ganz besonders: „Schopenhauer hat im Teufelspakt das Mythologem der Gattung gesehen. Nicht jener Doktor zwischen Mittelalter und Neuzeit hat das pactum geschlossen - wir alle finden es als das geschlossene und besiegelte mit und in unserer Existenz vor. Leben ist nur die Galgenfrist der Wette, und wir füttern emsig den Deliquenten, der doch hängen muß.“ (Blumenberg 1999: 207)

Was bei Marlowe eng miteinander verbunden ist, der unerbittliche Ablauf der Zeit einerseits, das Ende der individuellen Existenz andererseits, stellt sich bei Goethe anders dar. Goethes Faust hat keine Angst vor seinem Ende, sondern vor seiner Endlichkeit, die ihn beschränkt. Insofern räumt Goethe dem Tod keine Macht über seinen Helden ein, wohl aber der Zeit, die in beiden Teilen des Dramas ein zentrales Thema ist; sein Pakt mit dem Teufel beruht bekanntlich auf einer Zeitwette.

\section{Der säkularisierte Mephistopheles}

Goethe veröffentlichte sein Faustfragment 1790; der abgeschlossene erste Teil erschien 1808, der zweite Teil des Faust posthum 1832. Zwischen Marlowe und Goethe liegen, geistesgeschichtlich gesehen, die zwei Jahr- 
hunderte, in denen das moderne wissenschaftliche Weltbild entstand und die Aufklärung von Westeuropa aus ihren Siegeszug antrat. Die mittelalterliche Zweiweltenlehre verlor in dieser Zeit ihre Bedeutung unter den Gebildeten. Wenn Madame de Staël sich danach noch Mephistopheles grimmiger wünschte (s.o.), so war das ein rein ästhetischer Einwand, denn die intellektuelle Elite in Europa glaubte zu Beginn des 19. Jahrhunderts nicht mehr an die Existenz des christlichen Teufels.

Im Zentrum von Goethes Stück stehen das neue, bürgerliche Individuum, dem es um schrankenlose Selbstverwirklichung geht, sowie die daraus resultierenden Konflikte und Aporien. Faust wird die Hauptfigur allerdings erst durch den Teufelspakt. Ohne Mephisto keinen Faust - der Teufel ist vom Stoff grundsätzlich vorgegeben, weshalb es beispielsweise unangemessen ist, von Joseph Conrads Heart of Darkness als der wichtigsten Fortführung des Faust-Mythos in der englischsprachigen Literatur zu sprechen (so MCALINDON 1994: 11).

Einerseits war die Figur des Teufels also gefordert, andererseits fehlte ihr nach Aufklärung und Französischer Revolution eigentlich die Existenzgrundlage, denn der christliche Rahmen, in dem der Pakt mit dem Teufel Ende des 16. Jahrhunderts noch Sinn gemacht hatte, war entfallen. Deshalb war die Lösung, Faust in die Hölle fahren zu lassen, obsolet und wurde schon von Lessing abgeschafft. Selbst die Diskussion über den Ort bzw. der Hölle, die höllische Hierarchie, die Macht der Teufel etc., welche in der Historia wie bei Marlowe zwischen den beiden Antagonisten noch breit geführt wird, war zu Goethes Zeiten dem gebildeten Publikum nicht mehr zuzumuten. Folglich wird im gesamten Faust an keiner Stelle mehr darüber diskutiert, ist die Hölle einfach kein Thema mehr; nur ganz zum Schluss taucht sie einmal als Atrappe auf (dazu weiter unten).

Welche Lösung hat Goethe unter diesen Ausgangsbedingungen für seinen Teufel gefunden? Wenn Faust das neue, sich autonom dünkende Individuum repräsentiert, könnte sein Gegenspieler vielleicht für das Alte stehen - so eine These von Boyle (Boyle 2003: 764) -, also für eine Welt, die überwunden werden muss, damit sich das Neue durchsetzt? Die Figur des Mephistopheles weist in eine andere Richtung. In der Szene Hexenkiuche gibt uns der Teufel eine seiner beiden Selbstdarstellungen im ersten Teil des Dramas: 


\section{DIE HEXE (tanzend.)}

Sinn und Verstand verlier' ich schier,

Seh' ich den Junker Satan wieder hier!

\section{MEPHISTOPHELES}

Den Namen, Weib, verbitt' ich mir!

DIE HEXE

Warum? Was hat er Euch getan?

\section{MEPHISTOPHELES}

Er ist schon lang' ins Fabelbuch geschrieben;

Allein die Menschen sind nichts besser dran,

Den Bösen sind sie los, die Bösen sind geblieben.

Du nennst mich Herr Baron, so ist die Sache gut;

Ich bin ein Kavalier, wie andre Kavaliere.

Du zweifelst nicht an meinem edlen Blut;

Sieh her, das ist das Wappen, das ich führe!

(Er macht eine unanständige Gebärde.) (V. 2503ff.)

Was bei Marlowe von Faustus noch ketzerisch formuliert wird („I think hell's a fable"), um im Anschluss daran sofort dementiert zu werden, äußert hier der Teufel selbst, der sich zumindest an dieser Stelle keine Illusionen über seinen Status macht: „Den Bösen sind sie los“, der christliche Satan ist zu einer Märchenfigur geworden, steht im Fabelbuch. Wer ihn ersetzt hat, sind die vielen Bösen. Sie sind keine grimmigen Schreckensgestalten mehr, sondern Kavaliere, die sich zu benehmen wissen. Der Ausdruck Herr Baron verweist auf die Macht des Geldes, denn Baron war der käufliche Adelstitel der Zeit (vgl. den Kommentar in GAIER, KI 1999: 312). Später wurden im Deutschen Komposita wie Finanz-, Industrie- und Schlotbaron populär. Es ist also ein moderner Teufel, ein Geldmensch der Goethezeit, der sich hier in mittelalterlicher Kulisse vorstellt. Im weiteren Verlauf der Szene bekommt Faust auf Mephistos Veranlassung dann den Zaubertrank, der ihn um etliche Jahre äußerlich verjüngt und als Aphrodisiakum wirkt. Wie modern übrigens auch das ist, kann man erst heutzutage wirklich würdigen, wo Schönheitschirurgie und Viagrakonsum inzwischen der Normalfall geworden sind.

Die Hexenküche kann ein Prinzip deutlich machen, das im ersten Teil des Stücks und noch stärker dann im Teil II zur Geltung kommt: Raum, 
Zeit und Figuren decken sich nicht. Jedenfalls lassen sich Natürlichkeit und illusionistische Mimesis, zentrale Maßstäbe des von Lessing und Schiller gerade erst entwickelten bürgerlichen Dramas, in Goethes Faust nur sehr begrenzt finden. So treten in der Szene Innerer Burghof Figuren aus der antiken griechischen Literatur in einer Burg aus dem deutschen Mittelalter auf und das Geschehen in der mittelalterlichen Hexenküche hat eine zeitgeschichtlich bedeutsame Dimension, indem es auf Zustände im vorrevolutionären Paris des späten 18. Jahrhunderts verweist, wie alle Kommentare vermerken.

Ähnlich kann auch der Himmel verstanden werden, wie er im Prolog des Stücks inszeniert wird. Es ist ein Theaterhimmel, der vom Theaterdirektor zuvor als Attraktion angekündigt wird (V. 242). Gott residiert dort wie ein älterer absolutistischer Herrscher, und der zum Hofstaat gehörige Teufel, der in der christlichen Mythologie keineswegs freien Zugang zum Himmel hat, nimmt die Rolle des Hofnarren ein. Nach der pompösen Eröffnung des Zeremoniells durch die Erzengel und dem folgenden Dialog zwischen Gott und Mephisto gibt Goethe die Regieanweisung „Der Himmel schließßt" und lässt Mephisto einen letzten, ironisch-respektlosen Vierzeiler sprechen. Bis zum Schluss des zweiten Teils wird sich der Himmel nicht wieder öffnen; in das eigentliche Drama, das sich im folgenden auf der Erde abspielt, greift der Herr weder direkt noch indirekt durch himmlische Abgesandte ein.

Im Unterschied zu den Engeln, mit deren kosmologischen Hymnus die Szene beginnt, ist Mephistos Interesse an der Schöpfung begrenzt: „Von Sonn' und Welten weiß ich nichts zu sagen / ich sehe nur, wie sich die Menschen plagen“ (V. 279f.). Er ist nicht der große Gegenspieler Gottes im Kosmos, sondern als Teil der himmlischen Hierarchie, zum Gesinde gehörend, wie er es nennt (V. 274), so etwas wie der himmlische Beauftragte für die Menschen, von denen er einzig redet. Die Kommentatoren verweisen für den Dialog zwischen Gott und Mephisto zu Recht auf eine biblische Vorlage, nämlich auf die Abmachung zwischen Gott und Satan im Alten Testament, Hiob auf die Probe zu stellen (Hiob 1,1). Wer ausgehend vom Prolog allerdings eine Hiob-Geschichte erwartet, wird im Folgenden wenig verstehen, denn Faust hat mit Hiob kaum etwas gemeinsam. Auch sonst kann einiges, was hier im Prolog im Plauderton ausgesprochen wird, theologisch nicht überzeugen: Der von Gott gern gesehene Teufel 
(V. 273) äußert an mehreren Stellen offen Mitleid mit den Menschen, die es nicht leicht haben auf der Erde. Gott bezeichnet den Atheisten Faust irrigerweise als seinen „Knecht" (V.299) und erhält darauf sofort die passende ironische Antwort. Mephistos Auftrag, den er vom Herrn bekommt (V. 340ff.), beruht auf falschen Voraussetzungen, denn Faust ist sicherlich niemand, dessen Tätigkeit leicht „erschlafft“, der die Ruhe liebt und deshalb vom Teufel immer wieder angetrieben werden muss. Was Mephisto das Stück über versuchen muss, ist genau das Gegenteil, nämlich Faust zur Ruhe und zum Genuss des Augenblicks zu verleiten.

Die im Faust auftretenden „christlich-kirchlichen Figuren“ (Goethe zu Eckermann am 6. 6. 1831) werden in diesem Prolog also aus einer ironisch-aufgeklärten Perspektive vorgeführt und verlieren damit die Bedeutung, die ihnen traditionellerweise zukommt. Sie werden mythologisiert. Alwin Binder entwik-kelt die These, in dieser Posse werde dargestellt, ,wie sich das bürgerliche Bewusstsein ,Himmel', ,Gott' und ,Teufel' wünscht“ (BINDER 2003, 272), spricht gar vom Marionetten-Theater des bürgerlichen Bewusstseins, das im Prolog aufgeführt werde. Demzufolge würde es sich weder um einen christlichen noch um einen spezifisch goethischen, sondern um einen faustischen Himmel handeln. Auf jeden Fall bleibt festzuhalten, dass Mephisto auch im Prolog nicht im christlich-kirchlichen Sinne zu verstehen ist und der göttliche Auftrag an ihn, die Menschen nicht erschlaffen zu lassen, mit seiner Selbstdarstellung als moderner weltlicher Teufel in der Hexenküche bestens vereinbar ist.

Wie sehr Mephisto von dieser Welt ist, lässt sich interessanterweise gerade an denjenigen seiner Aktionen ablesen, die das am wenigsten vermuten lassen - an seinen Zaubereien. Traditionellerweise ist der Teufel als übernatürliches Wesen auch mit übernatürlichen Kräften ausgestattet, die er gegen den Menschen verwendet. Mephisto stellt aufgrund des Paktes alle seine Kräfte in den Dienst von Faust. In seinem Aufsatz „Faust und Mephistopheles" hat Georg Lukács als erster danach gefragt, was von Mephistos Magie gesellschaftlich zu halten ist und sie mit den kapitalistischen Produktivkräften in Verbindung gebracht, deren Entwicklung in der Phase der industriellen Revolution Goethe noch aufmerksam begleitet hat. Ob der Zauberflug am Ende der Schülerszene, die Erfindung des Papiergeldes im 1. Akt von Teil II, die Siebenmeilenstiefel oder die allegorischen Lumpen im 4. Akt: Ihrem Wesen 
nach unterscheidet sich diese Zauberei nicht von dem, was, wie im Falle von Ballonflug und Assignaten (Papiergeld der französischen Revolution), bereits realisiert war oder was sich technisch bzw. gesellschaftlich als möglich abzeichnete. Insofern handelt es sich um unmagische Magie, so wie Mephisto ein unteuflischer Teufel ist. Die wirklichen Wunder werden nicht mehr durch Zauberei, sie werden durch Geld bewirkt, auch darauf weist Mephisto an einer Stelle hin (V. 1824-27), die schon den jungen Marx inspiriert hat.

Das Thema Magie ist in beiden Teilen des Faust sehr komplex, längst nicht alles ist als ,unmagische Magie‘ verstehbar, beispielsweise nicht die Zaubertricks in der Szene Auerbachs Keller in Faust I. Mephistos Zaubereien wirken dort nicht gerade modern, sie gleichen vielmehr denen aus den Faustgeschichten des 16. Jahrhunderts. Sowohl in der Historia als auch bei Marlowe nutzt der Held seine durch das Bündnis mit dem Teufel gewonnene magische Macht, um allerlei derb-komische Streiche durchzuführen. So zaubert Marlowes Faustus dem Papst in Rom das Essen vom Teller und den Wein aus dem Glas oder einem Ritter am Hofe des Kaisers ein Geweih auf den Kopf; in anderen Szenen tritt er mit künstlichem Kopf auf oder lässt sich ein Bein ausreißen. Faust war es auch, der im Urfaust den Weinzauber in Auerbachs Keller veranstaltete, aber bei der Überarbeitung der Szene für die Veröffentlichung des Fragments hat Goethe sich dafür entschieden, Mephisto den Zauber durchführen zu lassen - weil es zur Konzeption dieser Figur hervorragend passt, wie man annehmen darf.

Es ist eine quasi didaktische Veranstaltung, die Faust, der in der Szene nichts weiter als Zuschauer ist, in Auerbachs Keller präsentiert wird. Wes Geistes Kind sie sind, machen die vier Zecher schon deutlich, bevor Faust und Mephisto eintreten, nämlich in der Art und Weise, wie sie über das andere Geschlecht reden. Mephisto führt ihre Beschränktheit und Dummheit dann schonungslos vor. Mindestens zwei von ihnen studieren anscheinend an einer Universität ${ }^{4}$, aber gelernt, sich ihres eigenen Verstandes zu bedienen, wie es in einem berühmten Satz von Kant heißt, haben sie nicht. Sie verwechseln die Freiheit mit Saufen von billigem Wein und sind schnell bereit, die Messer zu ziehen, um sich gegenseitig die Nasen abzu-

4 S. GAIER KI 1999: 276, zu der Frage, ob es sich um Studenten oder Spießbürger handelt. 
schneiden. „Gib nur erst acht, die Bestialität / wird sich gar herrlich offenbaren“, bemerkt Mephisto zu Faust, den die Vorstellung wohl anödet. Der teuflische „Hokuspokus' deckt das Bestialische, Kannibalische der „undurchdachten Ideologien“ (GAIER KI 1999: 277) auf. Insofern führt Mephistos Zauberei zu Desillusionierung statt zu Illusionierung. In Auerbachs Keller agiert ein aufgeklärter Teufel, der das Böse nicht produziert, sondern entlarvt.

\section{Der Schalk}

Ian Watt, der von der Faustgeschichte fasziniert, aber zugegebenermaßen kein Anhänger Goethes ist, bemerkt zu dessen Faust: „Faltam-lhe por completo tanto a capacidade de autocrítica quanto o senso de humor“ und fügt etwas maliziös hinzu: „Nesse ponto ele e seu criador parecem." (WATT 1997: 208) Diese Bemerkung wird beiden, dem Helden des Dramas und seinem Erschaffer, insofern nicht gerecht, als sie unterschlägt, dass Goethe dem Faust ein Alter Ego beigegeben hat. Die Figur des Mephistopheles sorgt dafür, dass sowohl Kritik als auch Humor in beiden Teilen des Dramas nicht zu kurz kommen. Wenn es überhaupt so etwas wie eine Grunddisposition in Mephistos Wesen gibt, dann eine skeptisch-spöttische. Schon im Prolog vom Herrn selbst als sein „Schalk“ bezeichnet, wird er diese Rolle bis zum Schluss hervorragend ausfüllen. „Ironie und Spott sind die Hauptingredienzien seines Wesens. [...] auch zu sich selber steht er in fast ungläubiger Distanz. Manchmal hat es den Anschein, als bezweifle er nicht nur das Gute, sondern auch das Böse“" (Michelsen 2000: 184). Mephisto tritt auf als eine „Kommentarfigur mit Eigenschaften eines intellektuellen Narren“ (EIBL 2000: 107). Der Narr hat in der Faustliteratur Tradition, in Marlowes Stück sind es die beiden Narren Robin the Clown und Rafe, die außer anderen komischen Nebenfiguren und Doctor Faustus selbst für die Erheiterung im Drama sorgen.

In Goethes Faust treten im Vorspiel auf dem Theater neben dem Theaterdirektor und dem Dichter auch eine Lustige Person auf, der Gracioso in der Übersetzung von D’Ornellas, Bufo bei Jenny Klabin Segall. Die Lustige Person ist im europäischen Theater der Neuzeit als Arlecchino, Pickelhering, Gracioso, Hanswurst u.a. ein fester Typus. Sie hat das 
Publikum zu amüsieren; häufig ist sie in der Rolle eines Bedienten Kontrastfigur auf sozial niederer Ebene, um die Tugenden und die Gefühle des Helden aus der Perspektive des gesunden Menschenverstands zu kommentieren und zu parodieren. Außerdem liebt sie es, sich durch das Sprechen ad spectatores direkt an das Publikum zu wenden und so die Illusion des Spiels zu missachten. In Goethes Vorspiel verkörpert die Lustige Person die Interessen der Schauspieler, redet lieber von „Mitwelt“ statt von „Nachwelt“ und bringt des Dichters hohe Idealvorstellungen von Olymp, Göttern etc. in zwei Zeilen zum Absturz, indem sie die dichterischen „Kräfte“ auf „Geschäfte“ reimt (V. 159f., vgl. SCHмidT 1999: 55). ${ }^{5}$

Wenn das eigentliche Spiel beginnt, hat Mephistopheles alle oben erwähnten Funktionen der Lustigen Person in seiner Rolle übernommen. Vor allem ist er, wie kaum eine andere Bühnenfigur der Theatergeschichte, ein Meister des uneigentlichen Sprechens, auf diesem Gebiet beherrscht er alle Register. Im Zusammenspiel mit seinen Kontrahenten produziert Mephisto immer wieder feinste Dialogkomik. Ein schönes Beispiel dafür ist sein Treffen mit dem Baccalaureus in Faust II, Zweiter Akt, Szene Hochgewölbtes Gotisches Zimmer. Es handelt sich hier um eine neue Version der Schülerszene aus dem Ersten Teil und insofern auch um Wiederaufnahme des Themas Wissenschaftssatire, das den gesamten Faust leitmotivisch durchzieht. In diesem universitären Rahmen entfaltet sich ein Generationenkonflikt. Mephistopheles spielt den alten, im Rollstuhl sitzenden Gelehrten, der sich vom akademischen Nachwuchs scheinbar in die Enge treiben und belehren lässt, dass sich seine Sichtweise überholt hat. Eröffnet wird die Szene durch den hereinstürmenden jungen Baccalaureus, der mit einem Monolog beginnt. In vierhebigen, kurzen dynamischen Versen beklagt er den Zustand der Wissenschaft und seine eigenen Möglichkeiten innerhalb der verkommenen Institution Universität, wobei seine Selbstbezogenheit und Arroganz deutlich werden, „ich ist

5 Verständlicherweise wird die Rolle der Lustigen Person im Vorspiel oft von dem Schauspieler übernommen, der im Folgenden dann den Mephistopheles spielt, so auch von Gründgens in der berühmten Hamburger Inszenierung Ende er fünfziger Jahre. 
Bacc.

[...] Hat einer dreißig Jahr vorüber, So ist er schon so gut wie tot.

Am besten wär's euch zeitig totzuschlagen. Meph.

Der Teufel hat hier weiter nichts zu sagen.

Bacc.

Wenn ich nicht will, so darf kein Teufel sein. Meph.(abseits)

Der Teufel stellt dir nächstens doch ein Bein. (V. 6787ff.)

Im Anschluss an diesen rhetorischen Schlagabtausch hebt der Baccalaureus zu einem weiteren Monolog an und darf noch einmal seine IchBezogenheit ins Absurde steigern („Die Welt, sie war nicht, eh’ ich sie erschuf“, V. 6794), bevor er abgeht. Mephisto kommentiert abschlieBend: 
Wenn sich der Most auch ganz absurd gebärdet, Es gibt zuletzt doch noch e' Wein.

(Zu dem Jüngern Parterre, das nicht applaudiert.)

Ihr bleibt bei meinem Worte kalt,

Euch guten Kindern laß ich's gehen;

Bedenkt: der Teufel, der ist alt,

So werdet alt, ihn zu verstehen! (V. 6813ff.)

Meisterlich verbinden sich in der Baccalaureus-Szene, aus der hier nicht ausführlicher zitiert werden kann, Ironie und Sarkasmus mit abstraktem Räsonnieren, vermischen sich Bilder aus dem täglichen Leben mit anspruchsvollen Abstraktionen, wird mit Sprichwörtern und Sentenzen jongliert. Am Ende hat es Mephisto durch sein Spiel wieder einmal geschafft, die Beschränktheit des anderen bloßzustellen, obwohl Goethe gegenüber seinen Figuren nicht ungerecht ist und es der Baccalaureus mit dem Meister der ironischen Rede sprachlich durchaus aufnehmen kann.

Die hier zitierten Szenenausschnitte zeigen neben der erwähnten Vorliebe für uneigentliches Sprechen noch eine andere Eigenheit der mephistophelischen Rede. Mephisto liebt es, wie traditionellerweise die Lustige Person, das Bühnengeschehen zu kommentieren, entweder mitten in der Szene durch das Sprechen a parte (wie oben V. 6792) oder durch die direkte Ansprache ad spectatores. Letzteres hat grundsätzlich eine antiillusionistische Funktion. Die fiktionsexterne Anrede des Publikums bedeutet ein Heraustreten aus der Bühnenillusion; das Spiel wird auf diese Weise sozusagen vorgeführt und bekommt eine selbstreflexive, theaterbezogene Komponente. Mephistos Kommentare an das Publikum findet man häufig am Ende einer Szene, was wie in der Baccalaureus-Episode dazu führt, dass der Teufel auf diese Weise das letzte Wort behält. Das letzte Wort kann auch eine Geste sein, wie im Fall von Mephistos stummen Kommentar am Ende des 3. Aktes, der schlicht und einfach darin besteht, an den Bühnenrand zu treten und die Maske der Phorkyas abzunehmen, in der er den gesamten Akt über aufgetreten ist.

In erster Linie ist Mephistopheles allerdings die Kontrastfigur zu Faust, als dessen spiritus familiaris resp. Bedienter er nach Abschluss des Paktes fungiert. Die Neigung des gelehrten Helden zu Pathos und Schwärmerei konterkariert er oft mit ironisch-sarkastischen Einwänden. „O linguajar de 
Mefistófeles, na sua corrosiva negatividade, põe tudo à bulha, dessacraliza tudo, crenças e convicções. $\mathrm{O}$, alto' e o ,baixo' nele coexistem, aproximados em convívio derrisório; a tirada filosófica e o palavrão chulo podem alternarse [...]“, bemerkt Haroldo dos Campos (CAMpos 1981: 79).

Ein besonders deutliches Beispiel dafür findet sich in der Szene Wald und Höhle, wo Mephistopheles mit den Versen 3282ff. Fausts naturphilosophischen Überschwang als schlecht verhüllte Triebsublimierung demaskiert. "Que Fausto foi impedido de perder-se na masturbação, na verdade não cabe dúvida", kommentiert Harold Bloom Mephistos spöttische Rede (BLOOM 2001: 217). Von Fausts großen Worten bleibt nach Mephistos schonungsloser Gegenrede nicht mehr viel übrig, sie erweisen sich als sophistische Manipulation (vgl. BINDER 2003, Dialog 24). Zwischendurch bemerkt Mephisto ironisch: "Und kurz und gut, ich gönn Ihm das Vergnügen, / gelegentlich sich etwas vorzulügen" (V. 3297f.). Mit einem solchen Partner kann man sich und dem Publikum auf die Dauer nicht vormachen. Mephisto geht es nicht einfach darum, Faust Liebe zu Margarete in zynischer Weise auf den banalen Kern ihrer Triebhaftigkeit zu reduzieren, wie einige Kommentatoren meinen. Sein Auftritt in Wald und Höble hat zur Konsequenz, dass Faust am Ende der Szene die Verführung und wissentlich auch den Ruin Gretchens beschließt: "Mag ihr Geschick auf mich zusammenstürzen / Und sie mit mir zugrunde gehen!" (V. 3364f.). Zwar versucht Faust noch, die Schuld dafür anderen zu geben: "Du, Hölle, musstest dieses Opfer haben!" (V. 3361), doch der Kontext ist eindeutig. Es ist Faust, der "so ziemlich eingeteufelt" (V. 3371) handelt; er trägt dafür die Verantwortung, worüber von nun an keine noch so erhabene Rhetorik mehr hinwegtäuschen können wird. Das klargestellt zu haben, ist die Funktion Mephistos. Wer sich gegen diese Lesart sträubt, stelle sich die Szene Wald und Höble um Mephistos Auftritt gekürzt vor, lediglich den Eingangsmonolog Fausts bis V. 3250 umfassend: Zweifellos würde das Drama weiterhin unverändert seinen Lauf nehmen, den es nun einmal nimmt, aber wir wären um die entscheidenden Verse gebracht, in denen Faust, in der Auseinandersetzung mit Mephisto, schließlich so deutlich seine Position zu Margarete formuliert.

So souverän Mephisto mittels zersetzender Ironie die Selbsttäuschungen und Beschränktheiten der anderen Figuren vorführt, so unbeteiligt bleibt er selbst im Grunde. Wie es sich für einen richtigen Schalk gehört, agiert er 
in Funktion der anderen ohne selbst involviert zu sein und gibt nur selten etwas von sich preis. Das ändert sich lediglich im zweiten Akt von Teil II, wo er auf eigene Rechnung durch die Klassische Walpurgisnacht zieht, und dann entscheidend in der vorletzten Szene des Dramas, der Grablegung, wo Mephistopheles seinen letzten Auftritt hat.

„Que vamos fazer com uma cena tão surpreendentemente afrontosa?“ fragt Harold Bloom hinsichtlich der Grablegung Fausts, die zweifellos den Höhepunkt des Grotesken in einem an grotesken Gestalten und Vorgängen nicht gerade armen Drama darstellt. Goethe hat hier den Kampf der Teufel gegen die himmlischen Heerscharen um die Seele Fausts auf eine Art und Weise inszeniert, die im 19. Jahrhundert alle vor den Kopf stoßen musste, Christen verschiedener Konfessionen wie die Vertreter des bürgerlichen Fortschritts, rückwärtsgewandte Romantiker wie politisch Engagierte, später auch bürgerliche Realisten, Naturalisten usw. Als Bildvorlage bei der Ausarbeitung dieser Szene diente ein Kupferstich nach einem mittelalterlichen italienischen Fresko. Auf dem Bild streiten die Vertreter des Guten mit denen des Bösen um die Seelen, die in der Form von kleinen nackten Körpern aus den Mündern der gerade Verstorbenen entschlüpfen; dabei wird ein Seelchen entweder vom einem Teufel gepackt und in die Hölle gezogen oder von einem Engel nach oben gerettet. Diese Vorstellung von Körper und Seele ist uns heutzutage so fremd geworden, dass die Reproduktion des Stichs in den Kommentarbänden bei ScHÖNE oder GAIER sehr hilfreich ist, die Vorgänge während der Grablegung zu verstehen.

Zu Beginn der Szene wacht Mephisto am Leichnam Fausts, um sich dessen Seele, auf die er ein Anrecht hat, zu bemächtigen und klagt darüber, dass es früher für den Teufel viel einfacher war:

Uns geht's in allen Dingen schlecht!

Herkömmliche Gewohnheit, altes Recht,

Man kann auf gar nichts mehr vertrauen. (V. 11620-23)

Mephisto misstraut (zu Recht, wie sich herausstellt) seinen himmlischen Kontrahenten. Den mentalitätsgeschichtliche Hintergrund dafür, dass der sonst so progressive Mephisto hier in der Position des Zurückgebliebenen auftritt, bilden die gewandelten Vorstellungen über Körper und Seele: Dass 
die Seele eines Verstorbenen den Körper in Form eines Menschenfigürchens verlässt, um vom Teufel gepackt zu werden, muss schon dem gebildeten zeitgenössischen Publikum ziemlich grotesk-anachronistisch vorgekommen sein. Es hat viel Witz, wie sich Mephisto in dieser Situation über die neuen Zustände beklagt und den alten Zeiten nachtrauert. „Lobo em pele de cordeiro, o Demo advogando em causa propria, insiste na observância das ,regras do jogo"“ (CAMPOS 1981: 154). Mephisto ruft zu seiner Unterstützung nun Dickteufel und Dünnteufel herbei, die die Aufgabe haben, zum entscheidenden Zeitpunkt in Aktion zu treten und Fausts Seele zu fangen. Wie im Doctor Faustus öffnet sich die Hölle, „der greuliche Höllenrachen tut sich links auf" lautet die Regieanweisung. Es ist eine mittelalterliche Hölle, für deren Beschreibung Mephisto hier genauso viele Zeilen zur Verfügung hat wie der böse Engel in Marlowes B-Text. Goethe war selbstverständlich bewusst, was er seinem Publikum damit zumutete; den theatralischen Charakter des Ganzen unterstreicht er u. a. dadurch, dass Mephisto die Hölle zwei Zeilen zuvor als ein „Spiel“ bezeichnet (V. 11642).

Mit Auftritt der Engel gewinnt dieses Theater im Theater an Dynamik. Den Kampf gegen die Dickteufel mit den geraden und die Dünnteufel mit den krummen Hörnern können die Engel schließlich für sich entscheiden, weil sie mit den Rosenblüten Liebe verbreiten, was die Teufel nicht ertragen: diese ,stürzen ärschlings in die Hölle“ (V. 11738). Im „Krieg der Rosen und der Fürze“ (EIBL) ziehen die Vertreter der Hölle den Kürzeren. Selbst Mephisto, der gegen die Rosen zuerst ankämpft, vermag der Liebesbotschaft auf Dauer nicht zu widerstehen. Vom Chor der rosenstreuenden, ihren Popo schwingenden Engel eingekreist und ins Proszenium abgedrängt, bemächtigt sich der himmlische Eros seiner Person, allerdings in einer ganz besonderen Variante: „Ihr seid so hübsch, fürwahr, ich möcht' euch küssen“ heißt es in V. 11771. Später wünscht er sich von einem „langen Burschen“, der ihm besonders gefällt: „So sieh mich doch ein wenig lüstern an!“ und fährt fort:

Auch könntet ihr anständig-nackter gehen,

Das lange Faltenhemd ist übersittlich -

Sie wenden sich - von hinten anzusehen! -

Die Racker sind doch gar zu appetitlich! (V. 11796ff.) 
Dass Mephisto ausgerechnet von ,appetitlichen Knaben“ angezogen und besiegt wird, ist der Gipfel der Ironie in diesem katholischen Theater, das sich unter der Hand in ein schwules Spektakel verwandelt hat. Mephisto „no episódio do Enterramento (Grablegung) do II Fausto, pertence à raça dos demônios carnavalizados" (CAMPos 1981: 153). Schließlich erheben sich die Engel, „Faustens Unsterbliches entführend“, wie es in der Regieanweisung heißt, und lassen einen um seine Beute betrogenen und körperlich lädierten Teufel allein auf der Bühne zurück, dem nichts weiter übrig bleibt, als über die himmlischen Machenschaften zu lamentieren:

Bei wem soll ich mich nun beklagen?

Wer schafft mir mein erworbenes Recht?

Du bist getäuscht in deinen alten Tagen,

Du hast's verdient, es geht dir grimmig schlecht. (V. 11832ff.)

Der geprellte Teufel ist ein altes Motiv aus den geistlichen Spielen des Mittelalters, in denen die Hölle am Schluss immer verliert. Goethe hat das wiederaufgenommen und variiert, wobei sein Mephisto, der uns als aufgeklärter Skeptiker und souveräner Schalk das ganze Drama über beeindrukken konnte, nun selbst zu einer Witzfigur wird. Ulrich Gaier weist darauf hin, dass der Teufel in der Grablegung ,als der von der geschichtlichen Entwicklung längst Überholte objektiv komisch wird“ (GAIER KI 1999: 1107). Aber nicht nur er, auch die Abgesandten des Himmels entgehen Goethes mythologischer Komik nicht. „Diese sehr ernsten Scherze“, wie Goethe in seinem vielzitierten letzten Brief an Wilhelm von Humboldt formuliert, beruhen letztlich darauf, dass hier christliche Mythologie so inszeniert ist, wie in der klassischen Walpurgisnacht griechische Mythologie inszeniert wurde (s. ScHмidT 1999: 288).

\section{Der Negative}

Diabo, Teufel, devil, diavolo etc. leiten sich etymologisch alle von lat. diabolus ab, dies wiederum von griechisch diábolos mit der Bedeutung, Verleumder, Ankläger', was eine Lehnübersetzung des hebräischen Satan aus dem Alten Testament darstellt. Der Satan der Hiobgeschichte ist der Wider- 
sacher des Menschen vor Gott, der Verleumder, der schlecht über Hiob redet. Mephistos Funktion in Goethes Faust, das hatten wir schon gesehen, ist ähnlich der eines Anwalts der Gegenpartei vor Gericht: Er bringt die Anderen zum Reden, versucht sie in Widersprüche zu verwickeln, ihre Defekte vorzuführen. Als Gegenspieler hat er keinen eigenen Standpunkt, sondern lebt im wesentlichen von der Negation. Die personifizierte Negation spielt er im 3. Akt von Teil II in der Rolle der Phorkyas, der hässlichsten Alten der griechischen Mythologie, als Gegenfigur zu Helena, der Verkörperung der Schönheit. In dieser Rolle ist der Teufel derjenige, der Helenas Bedingtheit verdeutlicht, indem er sie aus dem unhistorischen Mythos in die menschliche Geschichte holt, aus der sie am Ende wieder verschwinden wird.

$\mathrm{Zu}$ Beginn des 4. Akts kehrt Mephisto in seiner üblichen Gestalt auf die Bühne zurück, um wieder den Partner und Gegenspieler Fausts zu spielen. Auch sprachlich macht Goethe den Gegensatz zwischen den beiden deutlich. An dieser Stelle (Beginn der Szene Hochgebirg) ist es so, dass Faust in sechshebigen reimlosen Versen spricht, die griechischem Muster nachgebildet sind - er kommt nämlich gerade aus Arkadien, hat das Zusammenleben mit Helena hinter sich. Inmitten von Fausts feierlicher Rede tritt Mephistopheles plötzlich in Siebenmeilenstiefel auf, ganz Vertreter des schnellen Voranschreitens, des Fortschritts („Das heiß’ ich endlich vorgeschritten!“, V. 10067) und setzt gegen das erhabene Metrum Fausts seinen unregelmäßigen Madrigalvers, in dem er gewöhnlich redet.

Mephistos rasanter Auftritt leitet hier zum Geschehen der letzten beiden Akte über, in denen er im Wesentlichen nicht als Gegenspieler, sondern als Komplize Fausts agiert. Beherrschendes Thema ist von nun an die „Ambivalenz des modernen Fortschritts“ (so ein Kapitel bei SснміDт 1999). Repräsentant des Fortschritts war Mephisto schon vorher, beispielsweise in der Szene Kaiserliche Pfaly, Thronsaal (1. Akt), wo der Kanzler die alte feudale Ordnung und die klerikale Ideologie vertritt, während Mephisto wieder einmal als Gegenspieler fungiert, hier als aufgeklärter Praktiker und Modernisierer, der das Papiergeld einführt. In den letzten beiden Akten hat Mephisto dann die Aufgabe, für die Mittel zur Verwirklichung des Projekts zu sorgen, das von Faust in der Szene Hochgebirg entworfen wurde („Herrschaft gewinn ich, Eigentum!“ V. 10187). Nun wird ein Krieg gewonnen, 
ein Hafen gebaut, der freie Handel eingeführt und diejenigen, die für die neuen kapitalistischen Zeiten kein Opfer bringen wollen, weil sie am Alten hängen wie Philemon und Baucis, werden brutal beseitigt - alles mit Hilfe von Mephistos drei Gewaltigen. Schließlich folgt dann noch das Landgewinnungsprojekt, zu dem die Arbeitermassen gelockt und gepresst werden: „Arbeiter schaffe Meng’ auf Menge, / Ermuntere durch Genuß und Strenge, / Bezahle, locke, presse bei!“ (V. 11552 ff.) lauten die Anweisungen Fausts an seinen Aufseher Mephisto.

In den Dimensionen der ,großen Welt“ und unter der Zielvorgabe Fausts entwickelt Mephistos Magie zerstörerische Züge. Sie dient dem bürgerlichen Fortschritt und der Manipulation bisher eher naturhafter Verhältnisse, ohne irgendwelche Rücksicht auf Verluste zu nehmen. „So wird unter ,Magie' und den Bildern der Zauberei eine Allegorese der Moderne sichtbar“ (HENKEL 1993: 136). Schon früh hat dies auch Georg Lukács bemerkt, allerdings hegelianisch-kommunistisch gerechtfertigt mit den notwendigen Opfern, die eben für das Ziel der Geschichte gebracht werden müssen: „Es handelt sich bei Goethe nie um eine romantische Trauer über die Vernichtung der vorkapitalistischen Idylle. (Darum gibt es bei Faust selbst keine Reue über die Schuld am Untergang von Philemon und Baucis.) Goethe steht zu den Problemen der kapitalistischen Entwicklung so wie Hegel oder Ricardo." (LukÁcs 1967: 178)

Bei dem Unternehmen in Faust II, die alten Verhältnisse in faustische umzuwandeln, eine moderne bürgerliche Welt zu schaffen, fungiert Mephisto wie ein Manager, ein höherer Angestellter. Er stellt die Mittel bereit, die ihre destruktive Dynamik dann im Folgenden unerbittlich entfalten. Beide Gegenspieler sind derart aufeinander bezogen, dass es durchaus Sinn macht, ihr Verhältnis aus der Perspektive der Hegelschen Herr-Knecht-Beziehung zu analysieren. Was Faust erschafft, das gelingt ihm nur in der (und durch die) Interaktion mit Mephisto, dieser wiederum ist nicht in der Lage, selbständig, auf eigene Rechnung zu handeln. Faust gegenüber ist er als säkularisierter Teufel, der mit nichts mehr drohen kann, machtlos. Dennoch nimmt er eine eigenständige Position ein, die in ihrer absoluten Negativität ziemlich unhegelianisch ist, weil durch keine SubjektObjekt-Dialektik aufhebbar: 
Ich bin der Geist, der stets verneint!

Und das mit Recht; denn alles, was entsteht, Ist wert, dass es zugrunde geht;

Drum besser wär's, daß nichts entstünde.

So ist denn alles, was ihr Sünde,

Zerstörung, kurz das Böse nennt,

Mein eigentliches Element. (V. 1338ff.)

Mephistos erster Auftritt in Fausts Studierzimmer ist verbunden mit einer recht ausführlichen Selbstauslegung seines Wesens. Er stellt sich hier nicht als der Abgesandte einer wie auch immer gearteten Hölle dar, sondern als Vertreter des Nichts, philosophisch gesehen ein ontologischer Nihilist, der dem Sein seine letztgültige Wahrheit des Nicht-Seins entgegensetzt. Mephistos Standpunkt ist, wie es Michelsen in seinem lesenswerten Aufsatz formuliert, der des Futurum Exactum - alles was heute existiert, wird auch einmal gewesen sein, folglich hat das Nichts Priorität vor dem Sein. Böse ist diese Position nur insofern, als die Menschen sie so auffassen („,was ihr das Böse nennt"), wohl weil sie das Sein dem Nicht-Sein grundsätzlich vorziehen, dürfen wir Mephistos Rede an dieser Stelle ergänzen. Philosophie- bzw. religionsgeschichtlich gibt es hier eine Verbindung zur sogenannten Privationstheorie des Bösen: In der Tradition der theologischen Metaphysik hat das Böse keinen eigenen Standpunkt, sondern ist privatio dei, die Abwesenheit, der Mangel des Guten, woraus sich die Bestimmung des Bösen als eine Art Nichts ergibt, vgl. dazu den Überblick bei STRASSER 2000: $245 \mathrm{ff}$.

Mephisto hat seine Position mit diesen Worten metaphysisch verankert und so eine Dimension bekommen, die über das Negieren in der jeweiligen Situation, über sein Spiel des advocatus diaboli hinausgeht. Er kann sogar derart grundsätzlich werden, dass ihn selbst sein anscheinend größter ,Erfolg“ in diesem Drama, das Ende von Fausts Existenz, nicht zufriedenstellen kann. Als der Chor Fausts Tod mit dem Satz „Es ist vorbei“ kommentiert, ärgert sich Mephisto darüber, dass diese Worte zumindest anerkennen, dass da einmal etwas bzw. jemand gewesen ist und verteidigt seine nihilistische Sicht: 
Vorbei! ein dummes Wort.

Warum vorbei?

Vorbei und reines Nicht, vollkommnes Einerlei!

Was soll uns denn das ew'ge Schaffen!

Geschaffenes zu nichts hinwegzuraffen!

$» \mathrm{Da}$ ist's vorbei!« Was ist daran zu lesen?

Es ist so gut, als wär' es nicht gewesen,

Und treibt sich doch im Kreis, als wenn es wäre.

Ich liebte mir dafür das Ewig-Leere. (V. 11595ff.)

Leider ist Mephistopheles kein ebenbürtiger Kontrahent beigegeben, der seinen Standpunkt so in Frage stellen könnte, wie er es selbst mit seinen Dialogpartnern zu tun pflegt - man wünschte es sich an dieser Stelle. Die verbale Radikalität dieses Anwalts des Nicht-Seins, der nicht nur das Existierende, sondern sogar eine vergangene Existenz leugnet, ist sicherlich beeindruckend, doch darf man nicht übersehen, wie sehr seine Macht begrenzt ist. Mephisto kann dem Sein im Grunde nichts anhaben, darauf weist er selbst hin, vgl. seine Rede in V. 1369ff., wo es u.a. heißt: „Und immer zirkuliert ein neues, frisches Blut. / So geht es fort, man möchte rasend werden!“ (V. 1372f.). Anders als Michelsen, der meint, dass die Klage Mephistos vorgetäuscht ist, nicht ernst genommen werden darf, verstehe ich diese Verse wörtlich. Mehr als das Ende von einzelnen Individuen kann der Goethesche Teufel nicht bewirken, sicher ist aber selbst das nicht - den Tod des hochbetagten Faust hat er jedenfalls nicht zu verantworten. Vor allem weiß er jedoch, dass mit dem Tod des einzelnen Lebewesens nur für die notwendige ständige Erneuerung des Lebens gesorgt wird: Mephisto tritt hier auf als der Verursacher des malum physicum, des mal natural, und hat als solcher seinen angestammten Platz innerhalb der Schöpfung. Böse im modernen Sinne ist das nicht; für Übel und Schuld auf der Welt, also das malum morale, das mal moral, kann man ihn deshalb nicht verantwortlich machen. ${ }^{6}$ Damit ist die grundsätzliche Frage nach dem Bösen in der Faustdichtung angesprochen, die nun noch erörtert werden soll.

6 Zur philosophischen Diskussion des Bösen, Fragen der Theodizee usw. siehe die hervorragende Arbeit von Susan Neiman, der ich viele Anregungen verdanke. 


\section{Das Böse in Goethes Faust}

Im Unterschied zu seinem Vorgänger bei Marlowe und zum Bösen der Historia ist Goethes Mephistopheles ein säkularisierter Teufel, der nicht mehr aus dem christlichen Dualismus zu verstehen ist. Das Faustdrama ist ein Spiel im Diesseits, dies ändern auch der Theaterhimmel im Prolog und die Pappmachéhölle in der Grablegung nicht, bestätigen im Gegenteil, dass der christliche Rahmen nicht mehr gilt.

Nach drüben ist die Aussicht uns verrannt;

Tor, wer dorthin die Augen blinzelnd richtet,

Sich über Wolken seinesgleichen dichtet!

betont Faust selbst in V. 11442ff., bevor ihn die Sorge - nicht irgendein Abgesandter der Hölle - mit Blindheit schlägt. Angesichts dieser Ausgangslage hat es die Figur des Teufels schwer. Goethes Mephistopheles ist nicht grimmig, wie eingangs bemerkt, weil ihm dazu jede Grundlage fehlt. Wenn die Hölle ihre Glaubenswirklichkeit verloren hat, kann deren Repräsentant nicht mehr glaubwürdig drohen. Der Ausgang der Auseinandersetzung zwischen den Kontrahenten Faust und Mephisto steht im Grunde von vornherein fest - der Teufel kann seine Beute nicht bekommen. „Höllenverbot für Fauste" hat Hans Blumenberg (BLumenBERG 1999) das genannt.

Im 15. Buch von Dichtung und Wabrheit hat Goethe darauf hingewiesen, dass der christliche Gott wie der Teufel keine poetischen Figuren sind. Dies wurde aus der Perspektive des Autors geschrieben, der die Arbeit seiner Dichterkollegen, in diesem Falle Miltons Paradise Lost, einschätzt und über seine eigenen poetischen Probleme nachdenkt (im Kontext geht es um die Prometheusfigur). Bei der Bearbeitung des Fauststoffes musste Goethe für den Teufel und das damit verbundene schwierige Problem des Bösen eine Lösung finden. Ausgeschlossen waren dabei irgendwelche Konzessionen an den Zeitgeist wie etwa die Effekthascherei mit dem Gruseligen. So beklagt sich der alte Goethe in einem Gespräch 1830 über die „allerneuste ultraromantische Richtung“ in der französischen Literatur, in der gerade Teufel, Hexen und Vampire en vogue waren: „Dergleichen ist pikant! Das wirkt! Nachdem aber das Publicum diese stark gepfefferte Speise einmal gekostet und sich daran gewöhnt hat, wird es nur immer nach Mehre- 
rem und Stärkerm begierig. [...] In diesem Jagen nach äußern Effectmitteln aber wird jedes tiefere Studium und jedes stufenweise gründliche Entwikkeln des Talents und Menschen von innen heraus ganz außer Acht gelassen.“ (GOETHE 1998: 31392f.)

Nach Aufklärung, bürgerlicher Revolution und de Sade wäre die naheliegende Lösung für das Teufelsproblem gewesen, Faust einen radikal bösen Partner beizugeben, der eben nicht mehr Abgesandter der Hölle, sondern menschlicher Natur ist. Mephistopheles hat ja auch zweifellos säkulare Züge, wie oben erörtert. Den großen Bösen hätte Goethe allerdings gegen seine persönlichen Überzeugungen auf die Bühne stellen müssen, denn ein manichäisches Welt- oder Menschenbild war ihm völlig fremd. „Das, was wir böse nennen, ist nur die andre Seite vom Guten“ ist ein in diesem Zusammenhang häufig zitierter Satz aus der Rede des jungen Goethe zu Ehren Shakespeares (1771). Entsprechend lässt sich Mephistopheles verstehen, wenn er auf Fausts Frage „Wer bist du denn?“ antwortet: „Ein Teil von jener Kraft, / Die stets das Böse will und stets das Gute schafft" (V. 1335f., vgl. dazu den Kommentar in Gaier 1999, dem ich an dieser Stelle folge, im Unterschied zum Kommentar bei ScHÖnE 2003). Über die Jahrzehnte hinweg findet man immer wieder ähnliche Hinweise in Goethes Korrespondenz, z. B. in frühen Briefen an Lavater, in Briefen an Schiller oder einem Brief an das Ehepaar Herder vom 7. Juni 1793, wo er sich in dieser Frage von Kant, dem zeitgenössischen Philosophen, den er am meisten geschätzt hat, abgrenzt: „Dagegen hat aber auch Kant seinen philosophischen Mantel, nachdem er ein langes Menschenleben gebraucht hat, ihn von mancherlei sudelhaften Vorurtheilen zu reinigen, freventlich mit dem Schandfleck des radicalen Bösen beschlabbert, damit doch auch Christen herbeigelockt werden, den Saum zu küssen." (GOETHE 1998: 4948)

Goethe hat sich mit der Figur des Mephistopheles - kein Mensch, aber in vielem sehr menschlich, eindeutig ein Teufel, doch mit weitgehend unteuflischem Charakter - für eine ganz andere Lösung entschieden. Der postchristliche Goethesche Teufel ist „,verfügbar für ein freies Spiel der Bedeutungen und Rollen, die er selber sich zuschreibt, oder in denen die anderen ihn wahrnehmen“ (SCHÖNE 2003, Kommentar: 168). Er ist ein Spieler seiner eigenen Rolle („Muss wieder recht den Teufel spielen“, V. 2010) in vielfältigen Masken und Verkleidungen, ein Mischwesen, manch- 
mal ein mittelalterlicher Dämon, dann wieder ein moderner Lucifer (von lat. lux) als Träger des Lichts, also ein Aufgeklärter. „Der Teufel wird zur reinen Metapher ohne Halt in einer selbständigen ,eigentlichen’ Bedeutung “ heißt es bei Eibl (EIBL 2000: 102). So ganz stimmt das nicht, denn Mephisto bezieht (auch) deutlich den Standpunkt des destruktiven Verneiners, verkörpert (auch) die reine Negativität. Aber selbst in dieser Position muss er sich letztlich dem Gang der Schöpfung unterordnen.

Den großen Bösen finden wir weder in Mephistopheles noch in einer anderen Figur; Goethe lässt ihn auch nicht in Gestalt des Satans in der Szene Walpurgisnacht auftreten, wie ursprünglich geplant und in einigen handschriftlichen Entwürfen überliefert. ${ }^{7}$ Allerdings drängt sich dem Leser oder Zuschauer unwillkürlich im Verlauf des Dramas die Frage nach dem Bösen und der moralischen Schuld des Protagonisten auf. Faust selbst handelt offensichtlich amoralisch und destruktiv. Seine Taten wie seine Unterlassungen verursachen im ersten Teil die Zerstörung einer Familie und den völligen Ruin eines jungen Mädchens; auch im zweiten Teil kommt es seinetwegen zu Gewaltverbrechen. Gretchen will er sofort besitzen, als er sie zum ersten Mal sieht, Helena ebenso (Szene Rittersaal, 1. Akt), Philemon und Baucis sind ihm im Weg und werden mit den Mitteln Mephistos beseitigt. Goethe zeigt uns mit Faust einen modernen Narziss, der nur auf sich, seine Bedürfnisse, seine Vorstellungen und seinen Willen konzentriert ist. Margarete ist eine ganz in der christlichen Moral befangene Figur, die in Mephisto den traditionellen ,Widersacher" spürt. Als sie aber am Ende der Szene Kerker, vor Schuld und Verzweiflung wahnsinnig geworden, ihre Angst vor dem Tod überwunden hat und sich Gott übergibt, merkt sie zum erstenmal, dass man Angst vor Menschen wie Faust haben muss. „Heinrich, mir graut's vor dir“ (V.4610) ist der letzte Satz, den sie sagt.

Dazu gibt es eine Kontroverse in der Fachliteratur, ausgelöst durch Albrecht Schönes Rekonstruktionsversuch der Szene Walpurgisnacht. Einen Überblick über die Problematik bietet Sснмірт 1999. Schönes These der Selbstzensur Goethes ist nur überzeugend, wenn man davon ausgeht, dass die Walpurgisnacht in der ,synagoga satanae' gipfeln sollte, der Satan als „häretischer Gegengott“ geplant war (SCHÖNE 1982: 151). Goethe vertritt aber keine manichäische Weltsicht im Faust. Vgl. auch ZABKA 1998. 
Bei alledem handelt Faust subjektiv mit den besten Absichten. Eine teuflische Gesinnung, die darin bestände, „das Böse als Böses zur Triebfeder in seine Maxime aufzunehmen“ (KANT Bd. 4: 686), ${ }^{8}$ hat er sicherlich nicht. Andererseits hat er auch keine moralische Richtschnur, sein Gewissen ist eindeutig unterentwickelt. Weil für ihn das Jenseits und damit auch die Hölle weggefallen sind, ist seine faustische Freiheit unbegrenzt. Human könnte diese Freiheit erst durch Begrenzung werden (so BINDER 2003), aber selbst Mephisto schränkt Faust nicht ein, im Gegenteil hilft er dabei, alle Grenzen zu überwinden. In seiner Grundlegung zur Metaphysik der Sitten hatte Kant 1785 darauf hingewiesen, dass die Grundgesetze der Moral mit rücksichtslosem Verhalten gegenüber anderen Menschen nicht vereinbar sind: „Der Mensch [...] existiert als Zweck an sich selbst, nicht bloß als Mittel zum beliebigen Gebrauche für diesen oder jenen Willen, sondern muß in allen seinen [...] Handlungen jederzeit zugleich als Zweck betrachtet werden." (KANT Bd. 4: 60) Ein solcher Maßstab ist der Faustfigur wesensfremd.

Fragen des Bösen und der Moral in Goethes Faustdichtung zu erörtern impliziert nicht zwangsläufig, Goethe habe mit dem Faust eine moralisch-didaktische Geschichte geschrieben. Es geht im Faustdramen nicht um den Kampf des Guten gegen das Böse, wie ihn der Autor der Historia über 200 Jahre vorher oder beispielsweise Paulo Coelho in Der Dämon und Fräulein Prym knapp 200 Jahre danach beschrieben haben. Doch lässt sich Goethes Text unter der Fragestellung lesen (und sicherlich auch inszenieren): Wie wird Böses produziert, wie entsteht das Böse unter den Menschen, ohne dass es noch den Bösen gibt? Das ist meiner Ansicht nach ein zentrales Thema im Faustdrama. Die Frage wird im Text nicht direkt gestellt, wie sie auch nicht direkt beantwortet wird. Es kann aber am Ende keinen Zweifel darüber geben, dass sich das Böse in diesem Drama nicht auf den Teufel schieben lässt, es vielmehr durch die handelnden Menschen selbst produziert wird.

Der Klassiker Goethe steht mit diesem Herangehen an die Frage nach dem Bösen in der Tradition der europäischen Aufklärung. Spätestens seit Rousseau in seinem Emile darauf hingewiesen hatte, dass die Menschen

\footnotetext{
s Diesen und viele andere Hinweise auf Kant findet man bei BINDER 2003.
} 
auf der Suche nach dem Urheber des Übels sich selbst befragen sollten, aber auch seitdem dessen Gegner Voltaire die Übel dieser Welt im Candide beschrieben hatte, konnten gebildete Europäer wissen, dass die Menschen für das moralisch Böse selbst verantwortlich sind. Schon Leibniz hatte bei der Erörterung des Begriffs der Theodizee, welcher die Güte des Schöpfers trotz des offensichtlich miserablen Zustandes der von ihm geschaffenen Welt rechtfertigt, deutlich gemacht, dass Übel und Schuld innerweltlich sind und ihren Ursprung in der Freiheit der Menschen haben. Goethes Welt- und Lebensspiel beinhaltet keine Theodizee im Leibnizschen Sinne; allerdings lässt sich dieser Begriff weiter fassen: „A teodicéia, no sentido estrito, permite ao crente conservar sua fé em Deus diante dos males do mundo. No sentido amplo, é uma maneira de dar significado ao mal que nos ajuda a encarar o desespero. As teodicéias inserem os males em estruturas que nos permitem continuar a viver no mundo." (NeIMan 2003: 264)

So aufgefasst handelt es sich im Faustdrama doch um eine Theodizee, besser noch um eine Anthropo- oder Homodizee (s. BindER 2003, Dialog 26). „Es irrt der Mensch, so lang’ er strebt“ (V. 317) lautet eine sprichwörtlich gewordene Bemerkung des Herrn zu Mephisto während ihrer Diskussion über Faust im Prolog, und in der letzten Szene des Stücks jubilieren die Engel: „Wer immer strebend sich bemüht, / Den können wir erlösen“ (V. 11936f.). Skandalös sind diese Sprüche nur für diejenigen, die die Figurenrede im Drama mit der Haltung des Autors verwechseln und meinen, Goethe wolle mit diesen Worten die Taten Fausts rechtfertigen, womöglich alle Verbrechen entschuldigen, zu denen faustische Menschen in der Lage sind. Mephistos Spott über solche moralischen Eiferer mag man sich leicht ausmalen. Wie Goethes Teufel allerdings zweihundert Jahre später spotten würde, ist wesentlich schwerer vorstellbar. Angesichts unserer sehr faustischen Gegenwart würden wahrscheinlich selbst ihm die passenden Worte schwerfallen.

\section{Literaturverzeichnis:}

BINDER, Alwin. Faustische Welt. Interpretation von Goethes Faust in dialogischer Form. Urfaust - Faust-Fragment - Faust I. Münster, LIT ${ }^{3} 2003$. 
BLOOM, Harold. O cânone ocidental: Os livros e a escola do tempo. Trad. Marcos Santarrita. Rio de Janeiro, Objetiva 2001.

Blumenberg, Hans. Goethe zum Beispiel. Frankfurt a. M., Leipzig, Insel 1999. Bosi, Alfredo. Dialética da colonização. São Paulo, Companhia das Letras ${ }^{4} 2001$.

Boyle, Nicholas. Goethe. The Poet and the Age. Vol. I: The Poetry of Desire (1749-1790). / Vol. II: Revolution and Renunciation (1790-1803). Oxford, Oxford University Press 1992 / 2003.

Campos, Haroldo de. Deus e o diabo no Fausto de Goethe. São Paulo, Perspectiva 1981.

Dinzelbacher, Peter (Hg.). Europäische Mentalitätsgeschichte. Hauptthemen in Einzeldarstellungen. Stuttgart, Kröner 1993.

EiBL, Karl. Das monumentale Ich. Wege zu Goethes 'Faust'. Frankfurt a. M. / Leipzig, Insel 2000.

GaIER, Ulrich. Faust-Dichtungen. Band 2: Kommentar I. Band 3: Kommentar II. Stuttgart, Reclam 1999.

Goethe, Johann Wolfgang. Briefe, Tagebücher, Gespräche. CD-ROM. Digitale Bibliothek Bd. 10. Berlin, Directmedia 1998.

Goethes Werke. Band 3: Faust I, Faust II, Urfaust. Hg. v. Erich Trunz. 11. neubearbeitete Auflage. München, Beck 1981.

Goethe, Johann Wolfgang. Faust. Bd. 1:Texte. Hg. v. Albrecht Schöne. Bd. 2 Kommentare von Albrecht ScHÖNE. Frankfurt a.M. / Leipzig, Insel 2003.

Henkel, Arthur. „Mephistopheles - oder der vertane Aufwand“ In: Cramer, Thomas / DAhlheIm, Werner (Hg.). Gegenspieler. München, Hanser 1993, $130-147$.

Historia von D. Johann Fausten. Text des Druckes von 1587. Kritische Ausgabe hg. von Stephan Füssel u. Hans Joachim Kreutzer. Stuttgart, Reclam 1999 (1988).

Kant, Immanuel. Werke in 6 Bänden. Hg. v. Wilhelm Weischedel. Bd. 4: Schriften zur Ethik und Religionsphilosophie. Sonderausgabe. Darmstadt, Wissenschaftliche Buchgesellschaft 1998. 
LuKÁcs, Georg. Faust und Faustus. Vom Drama der Menschengattung zur Tragödie der modernen Kunst. Ausgewählte Schriften II. Reinbek, Rowohlt 1967.

Marlowe, Christopher. Doctor Faustus and other plays. Ed. by D. Bevington and E. Rasmussen. Oxford / New York, Oxford University Press 1998.

Matussek, Peter. "Faust I" In: Buck, Theo (Hg.) Goethe-Handbuch. Bd. 2: Dramen. Stuttgart / Weimar, Metzler 1996, 352-390.

Michalzik, Peter. Gustav Gründgens. Der Schauspieler und die Macht. München, List 2001.

Michelsen, Peter. „Mephistos ,eigentliches Element’. Vom Bösen in Goethes Faust“" In: ders, Im Banne Fausts. Würzburg, 2000, 171-191.

McAlindon, Thomas. Doctor Faustus: divine in show. New York, Twayne, 1994.

NeIman, Susan. O mal no pensamento moderno. Uma bistória alternativa da filosofia. Trad. Fernanda Abreu. Rio de Janeiro, DIFEL 2003.

Prandi, Reginaldo. "Exu, de mensageiro a diabo. Sincretismo católico e demonização do orixá Exu” In: Revista USP 50/2001, 46-63.

Russell, Jeffrey Burton. The Prince of Darkness. Radical Evil and the Power of Good in History. Ithaca: Cornell University Press 1988.

ScHмiDT, Jochen. Goethes Faust. Erster und zweiter Teil. Grundlagen - Werk Wirkung. München, Beck 1999.

SCHÖNE, Albrecht. Götterzeichen - Liebesqauber - Satanskult. Neue Einblicke in alte Goethetexte. München, Beck 1982.

Strasser, Peter. Der Weg nach draußen. Skeptisches, metaphysisches und religiöses Denken. Frankfurt a. M., Suhrkamp 2000.

Watt, Ian. Mitos do individualismo moderno. Fausto, Dom Quixote, Dom Juan, Robinson Crusoe. Rio de Janeiro, Jorge Zahar 1997.

ZaBKA, Thomas. „Dialektik des Bösen. Warum es in Goethes ,Walpurgisnacht' keinen Satan gibt.“ In: Deutsche Vierteljabresschrift für Literaturwissenschaft und Geistesgeschichte 72, 1998, 201-226. 